\title{
Designing for Digital Playing Out
}

\author{
Gavin Wood', Thomas Dylan', \\ Abigail Durrant ${ }^{3}$, John Vines ${ }^{12}$, \\ Shawn Lawson ${ }^{13}$ \\ Northumbria University \\ Newcastle upon Tyne, UK \\ first.last@unn.ac.uk \\ Denise Downey ${ }^{8}$, Phil McGrath ${ }^{9}$ \\ The Cedarwood Trust \\ North Shields, UK \\ denise@cedarwoodtrust.co.uk
}

\author{
Pablo E. Torres ${ }^{4}$, Mutlu Cukurova ${ }^{7}$ \\ UCL Knowledge Lab, \\ UCL Institute of Education, \\ London, UK \\ first.last@ucl.ac.uk
}

\author{
Philip Ulrich ${ }^{5}$, Amanda Carr 6 \\ Canterbury Christ Church University \\ Canterbury, UK \\ first.last@canterbury.ac.uk
}

\author{
Alice Ferguson ${ }^{11}$ \\ Playing Out CIC, \\ Bristol, UK \\ alice@playingout.net
}

\author{
Madeline Balaam ${ }^{10}$ \\ Royal Institute of Technology (KTH), \\ Stockholm, Sweden \\ balaam@kth.s
}

\begin{abstract}
We report on a design-led study in the UK that aimed to understand barriers to children (aged 5 to 14 years) 'playing out' in their neighbourhood and explore the potential of the Internet of Things (IoT) for supporting children's free play that extends outdoors. The study forms a design ethnography, combining observational fieldwork with design prototyping and co-creative activities across four linked workshops, where we used BBC micro:bit devices to co-create new IoT designs with the participating children. Our collective account contributes new insights about the physical and interactive features of micro:bits that shaped play, gameplay, and social interaction in the workshops, illuminating an emerging design space for supporting 'digital playing out' that is grounded in empirical instances. We highlight opportunities for designing for digital playing out in ways that promote social negotiation, supports varying participation, allows for integrating cultural influences, and accounts for the weaving together of placemaking and play.
\end{abstract}

\section{KEYWORDS}

Digital playing out; children; outdoor play; open-ended play, pervasive play; Internet of Things

Permission to make digital or hard copies of all or part of this work for personal or classroom use is granted without fee provided that copies are not made or distributed for profit or commercial advantage and that copies bear this notice and the full citation on the first page. For all other uses, contact the Owner/Author.

CHI 2019, May 4-9, 2019, Glasgow, Scotland, UK

(C) 2019 Copyright is held by the owner/author(s). Publication rights licensed to ACM. ACM ISBN 978-1-4503-5970-2/19/05

https://doi.org/10.1145/3290605.3300909

\section{INTRODUCTION}

Social commentators in the UK have observed the significant decline of outdoor play [18,34,36,39,49,50], a phenomenon also recorded in many post-industrial societies e.g. [19,42]. More young people than ever are spending time indoors and "playing out" less. There are known contributing factors to this decline, and they include problems such as perceptions of neighborhood safety [9], concerns for increased traffic on roads [14], and increasing awareness of "stranger danger" [1,6]. Another major contributing factor to this decline is the increased consumption of screen-based media by children, where $95 \%$ of UK 5 to 11 -year-olds watch over 13.5 hours weekly [35] and even more (eight hours a day for 8 to 10-year-olds) in other countries such as the US [42], and attributed to the design innovations of interactive media entertainment. This phenomenon raises valid concerns about health, wellbeing and children's social development [10]. It also raises concern about community cohesion; many local places that might be previously associated with play, such as town squares, parks and other public spaces have become 'play deserts' [36]. Grassroots initiatives and advocacy groups have formed in recent years to address these issues [21].

In recent years, the field of Human-Computer Interaction (HCI) has developed a growing interest in promoting and designing for diverse notions of play $[2,25,43,45]$. While screen-based media entertainment is traditionally associated with indoor play that is often sedentary, innovations making use of computer vision [24], interactive television [30] and role-based games [15] have ushered in new indoor experiences with embodied, 
physical and social gameplay [46]. Today, this coincides with the incipient use of internet-connected smart toys, voice assistants and smart speakers in the homes of 1 of 10 children in the USA [42].

Most recently, researchers have started to explore how digital technologies may promote new forms of playful or recreational engagement with the outdoors [22], including the embedding of technologies in playground environments [4], the use of augmented reality to explore local environments [41] and experiences of pervasive gaming on social and physical activity [52]. Furthermore, the proliferation of sensor-based technologies and Internet of Things (IoT) devices has further created new opportunities to explore tangible play objects [8], and for play technologies that may extend more pervasively out from the home into the environment and neighbourhood beyond [4]. Arguably, this IoT design space for supporting pervasive play outdoors remains underexplored.

In this paper we report on a design ethnography [44] that set out to better understand barriers to children (aged 5 to 14 years) 'playing out' in their local neighbourhood, while also exploring the design potential of IoT for supporting free play that extends outdoors. The study is part of a project partnering with charitable organizations across the UK that support 'playing out' initiatives, and brings together academic expertise in design, computer science, psychology, and the learning sciences. The study we describe forms an ongoing Research-through-Design (RtD) inquiry [54] that is methodologically grounded in the ethnographic tradition [44] and combines observational fieldwork with prototyping and co-creative activities that are mutually informing. We describe our fieldwork based at the site of our local partner organization, where we coran a series of workshops with children. We also describe running an additional workshop in partnership with another local charity. Our aim through the RtD approach was to understand how children orientate to playing out, and to explore, with the children, the design of new IoT resources for open-ended, pervasive play in the emerging domain of digital playing out. By presenting an analytic account of this inquiry, we discuss how the children we worked with engaged with low-cost, accessible IoT technologies (including BBC micro:bit), to mediate and disrupt their outdoor play, and how they creatively appropriated the technology within their games and social interactions. Our analysis of field notes, photos, audio recordings, and hand-drawn sketches reveals how the physical features of IoT devices invite particular play behaviors that support social expression, negotiation and influence in new ways that are deeply connected to placemaking in the local community, and to cultural influences.

\section{PAPER AIMS AND CONTRIBUTIONS}

The contribution of this work is drawn across four workshops. Our empirical work began by developing an understanding of play in the neighborhood we studied, before focusing more on playing out with IoT. The RtD activities build on each other; our initial analytic insights on supporting children's existing outdoor play, ground and inspire conceptual IoT designs for extending and facilitating new forms of play outdoors. Through presenting our insights, organized as themes below, we aim to contribute substantive new transferable knowledge to HCI discourses in three ways. First, we extend understanding of pervasive play by empirically exploring the appropriation of IoT resources by children in playful activities that extend outdoors into the neighborhood, delivering qualitative findings from a UK setting. Second, we report on the observed functional features of IoT resources that invite particular social behaviors in the context of open-ended play, to inform future HCI design explorations. Finally, our methodological contribution to the Interaction Design for Children (IDC) community in HCI [40] is a case study of RtD that demonstrates the value of participatory, practice-based research that engages children with design prototypes for their creative appropriation.

\section{BACKGROUND}

Open-ended play with interactive technologies has been widely explored in the $\mathrm{HCI}$ and related IDC literature, to explore design potential for children to create their own personalised games and meaningful experiences [55]. The potential value of interaction design supporting play for enhancing children's wellbeing has been highlighted [31]. We focus on open-play rather than educational play for its positive role in children's development that will help them in later life [23], such as the development of resilience described by Ginsburg [16] that will help a child find ability to "bounce back" against adversity. We contextualize our work in mundane contexts of social interaction, where we explore how to design open-ended resources that may be creatively appropriated by children. 
There are a number of HCI studies of outdoor play that inform our work. Some are particularly design-oriented and have focused on interactive tangibles that encourage social interaction and physical play [7]. Such work may see design as interventional to free play, where designs serve as 'intermediary objects' and researchers embrace an ecological approach to studying children's engagement with their outdoor play environment [48]. In methodological terms, design methods like sketching may be enlisted in research to retain focus on the 'embodied interactional' nature of play where the setting is a critical feature of the design space [26,47].

Researchers have also critically examined the design of digital technologies to enhance outdoor play, identifying benefits but also potential risks, where digital interventions for outdoor play may compromise benefits [20]. HCI studies in this space have evaluated virtual versus tangible design artifacts for enriching outdoor play [52], highlighting how designing for outdoor play can engender new experiences distinct from play resulting from mobile phone games or game consoles, defining the value of 'Heads-Up-Games (HUGS)' for enhancing social interaction [53]. Others have demonstrated the value of pervasive, location-based design support for engaging with the places and spaces of the local neighbourhood [4].

Practice-based design research on pervasive play with IoT has appropriated off-the-shelf products to build and innovate with unique and bespoke technology configurations. For example, Hilton and colleagues speak to the Heads-up Games (HUG) paradigm by creating a 'real-time coding environment' that enables children to change gameplay rules in real-time [19]. These researchers offer valuable considerations for balancing societal concerns for increasing outdoor play with technological innovation in game design [19].

In our UK study we identified BBC micro:bit as a useful IoT resource for RtD. The BBC micro:bit is a low cost tiny programmable computer, designed to make teaching and learning programming fun. The BBC micro:bit can be programmed in a way that allows code to be dragged and dropped into graphical coding blocks which snap together to make programming logic easier to understand. micro:bits are proving ideal for outdoor play. They come with useful sensors including motion detection, compass and Bluetooth connectivity, and can be connected to other input/output boards extending how they can be used. Importantly, they are readily available and easy to learn: one million micro:bits had been given to every year 7 student in England and Wales with $90 \%$ of those students reporting that it showed them anyone can code [5].

What remains underexplored in extant work is how design for playing out with IoT may support social interaction and physical wellbeing and how these further connect to notions of community cohesion and placemaking. In respect to the latter, our work builds on $[12,37]$ who describe how public space can be subverted in ways that can be meaningful for children [37]; in doing so, we aim to open-up opportunities, adding important new voices as we re-make spaces owned by the community [12]. Also, we note that there is a dearth of research that methodically observes the physical properties and affordances of IoT technologies/ resources, which may be exploited by interaction designers for enhancing pervasive play outdoors.

\subsection{DESIGN ETHNOGRAPHY}

Our methodological approach to this study was designled, practice-based, and empirically grounded in a local community setting. It was positioned as a design ethnography [44]; we embedded ourselves as a team in the field site, and systematically conducted observation and co-creative activities with participants, capturing fieldnotes, photos and videos from the field. After Salvador et al [ibid.], our aim through our design ethnography was to make sense of children's experiences of playing out in their neighborhood, and to understand how they may creatively use IoT technologies as tools, to gather design inspiration for prototyping. Our collective empirical engagement and design prototyping practice has been interwoven and mutually informative, involving "the work of discovery" [ibid.] to generate rich idiographic insights.

The ethos behind our inquiry was to make constructive and creative interventions, ensuring that the IoT technologies that we configured for RtD were positioned as resources and building blocks for open-ended play rather than constraining and disruptive to it, inviting embodied interaction between people and environment.

Our point of departure was to engage with an understanding of play and gameplay as part of a child's social development (after Mead [32]). Although the evidence is mixed in terms of the actual importance that play may have in driving, rather than just co-occurring with child development [27], at the very least play can be argued to allow for children to practice the skills 

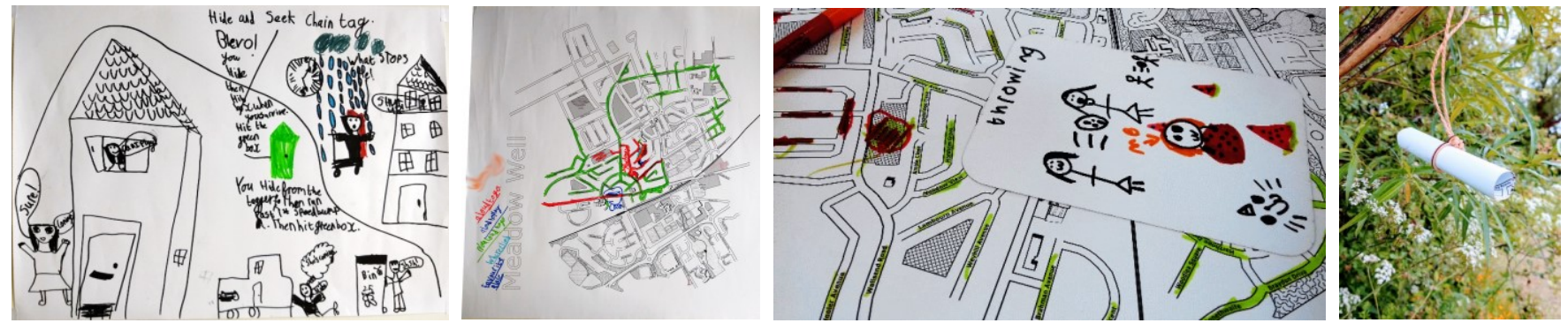

Figure 1. From left to right: (a) Poppy's drawing of play on the local estate; (b) Map activity (c) Card describing play (d) required to engage in play itself [38]. When engaged in playing open-ended games with rules, children tend to engage in adapting and creating new rules to make the game more fun and engaging [55]. This insight informed our approach. From the outset, we were careful to design our engagement with a theoretical commitment to support open-ended play in which games may be devised but where rules may be freely adapted in a creative and generative fashion [13]. Culturally positioning our study and team in the UK context, we were keen to introduce the notion of digital playing out with our partners by exploring how tangible IoT may connect with traditional, outdoor games like Hide and Seek, Tag, Wink Murder, British Bulldog, which are familiar to children and adults. These games opened-up a research dialogue at our field site.

\subsection{Our Key Field Site}

The main setting for the design ethnography has been a community development charity called The Cedarwood Trust (TCT) in a low economic area in the UK. TCT was established to provide opportunities to a community who are limited by poor average income and affected by a reduction in the provision of social services. Recently, the UK government has cut back on schemes such as Sure Start, which provided childcare, early education, health, family support, outreach and community development support to citizens [51]. TCT picks up from the point where many of these key services are now missed, providing much needed face-to-face support with local residents, financial advice, courses, activities for children (aged 2 to 12) and a day care facility to drop at off during the day and in the school holidays. TCT was awarded a government grant to renovate the old local community center which is now transformed into a welcoming place. There is an AstroTurf area for children to sit and play, while rooms adjacent to the main area contain formal seating and desks for educational activities and meetings. At the back of the main building is a playing yard and Play Lab, a mobile home erected in TCT's outdoor grounds that is used by the center's volunteers, entitled "Play Champions", who have been trained from the local area to supervise play. TCT and its staff are busiest during school holidays when children are at home and parents cannot take annual leave. The CEO of the charity describes the importance of Play Champions to keep children interested during these periods, and, schedule creative, themed activities schedules with original content that typically run from $10 \mathrm{am}$ to $3 \mathrm{pm}$. Play Champions will often move activities between the Play Lab and adjacent yard when the children get restless and need a change of activity. As such, TCT and their Play Lab provided a rich site to explore playing out, as children would often move between these indoor and outdoor spaces, and indeed the spaces surrounding the TCT centre. The founding director of TCT had a keen interest in the research and was central to the design of our study from its conception.

\subsection{Data Collection}

Our ethnographic engagement at TCT took place over a 12-month period, starting with initial fieldwork, and culminating in a series of workshops that built on each other. As well as working directly with TCT, we discussed our emerging insights with other child and play advocacy organisations to explore the wider applicability of our findings. We discuss each stage of our activities below.

\section{|lnitial fieldwork}

At the start of our engagement with TCT, our data collection was focused on participant-observation during Play Lab sessions, conducted by the first author. During these visits, field notes were made from both indoor and outdoor time, noting how TCT ran themed play activities that involved messy craft and paint, food, water and soil. These activities lent themselves to the outdoors where they benefited from more physical space and access to natural materials.

Interleaved with these initial visits, the project team held introductory discussions with the CEO of TCT, 
partnering organizations and stakeholders, and other children's play advocacy organizations. Alongside discussing the fieldwork, the team reviewed other published reports and available media on the barriers and enablers of outdoor play. This included reviewing recent news stories and media coverage of outdoor play initiatives (e.g. [29]), and the public responses on news websites and social media platforms. These discussions culminated in a roundtable, collocated brainstorming involving the entire project team, where we identified 'key barriers' to playing out in local neighborhoods.

Sensitizing concepts. This initial work supported the team with the ethnographic sensibility of 'gearing in' to the research context [17] and to get to know those who we would be designing things with. In keeping with our RtD approach, we were motivated by this sensitizing work to devise a set of concepts that would inspire and guide design sketching exercises - relating to the material language of design in terms of form and function, and therefore open-up a practice-based inquiry at TCT. These concepts included:

- Porous Thresholds: Engage children in a setting that invites and affords playing out, by lowering the threshold between indoor and outdoor space. We feel the barriers to getting young children to play out might be lowered by thinking about playing out as a small step, - thus, we consider getting them "out the door" with an intention to play out.

- Be Interventional: As part of the ethnography we aimed to make lightweight interventions during our field engagement, which would serve as fun provocations, inviting new experiences, new ways of thinking, and sometimes seeking to place new digital resources in the hands of the children;

- Hybrid interactions: Work with tools and games that are familiar to children under 9; introduce digital elements. Regarding them as experts of their own experience, children's descriptions of their own games and play will open-up a design space for augmenting play using IoT.

- Clear function, open purpose: Focus on design functionality that is clear to its users whilst leaving the purpose of use open to playful interpretation. e.g. IoT devices would be chosen for accessibility and may be provided to children as off-the-shelf components to combine, underscoring physical and digital affordances.
Collaborative sketching on these concepts led us to produce additional interaction metaphors for ongoing ideation: Magic Mirror; Lock and Key; Mystery Tour; Hide and Seek; Finders' Keepers; and Secret Signs. We presented both these ideas and the sensitizing concepts to the staff at TCT, as a starting point for the co-design of creative workshops. Discussions resulted in the articulation of an orientating theme of Secrets, Signs and Maps. This, in turn, informed the set of activities devised for the first workshop.

\subsection{Workshop 1: Secrets, signs and maps}

The first workshop (W1) was informed by conversations with the CEO and a shared interest in better understanding how children played within the boundaries of TCT and in the surrounding housing estate. Therefore, W1 was themed around "secrets, signs and maps" and conducted over the course of a single day, with activities broken up by breaks and lunch.

This workshop was split into four parts. First, children were asked about what they played, where, with whom and what barriers to play they experienced. Drawing was a prominent activity at TCT, and we therefore encouraged the children to draw or write examples of their play on to large sheets of paper (e.g. Figure 1a).

The second activity was a mapping exercise, beginning with orientating the children to a local map where they found where they lived and played, their favorite and most avoided places, the journeys they make through the estate (e.g. to school and back to home) and opportunities they found to play in those spaces (e.g. Figure $1 \mathrm{~b}$ ). This activity responded to discussions with the CEO who stressed the importance of the natural lines across roads which created micro-communities in the local area.

A third activity asked children to create symbols of their play and draw these onto cards (e.g. Figure 1c). These symbols were an opportunity for the children to further articulate the types of play they discussed in the earlier activities, and to communicate them to others.

The fourth and final exercise saw the children take the researchers on a tour around the local community, where we asked them to attach their play symbols in those locations where that play occurred. To do this, we gave the children a range of different laser cut plywood stands and hangers to place their cards in. Here, our intention was to gain a better sense of how they play in 
the neighbourhood by actually getting them outdoors and allowing us to visit their play spaces.

\subsection{Workshop 2: Exploring different examples of play}

The second workshop (W2) was conducted the day after W1 and was more flexibly structured around exploring the different examples of play that the children discussed and demonstrated to us the day before. The workshop began with researchers joining a morning warm-up exercise where children had been given materials and free-reign to draw what they wanted - an activity often led by the children's own interests. After this, we invited them to continue their drawings but talk about their play as they drew - which they invariably wrapped into their drawings. This would provide opportunity for the researchers to draw the play as it was described, which further encouraging children to respond in kind. As the day progressed, we regularly moved outside for fresh air breaks and opened ended-play, while responding to games the children were playing by introducing digital components, here using a game template that used PlayStation Move controllers as a readily programmable input/output system.

\subsection{Workshop 3: Developing Play Bits}

Following the second workshop, the team had developed a deeper understanding of the richness of play - both indoors and outdoors - for the children at TCT, as well as some of the barriers to be overcome. What was especially valuable from these initial activities is that they provided a diverse array of games that the children drew on, and often combined with each other, when playing outdoors. To start probing more explicitly the opportunities that IoT technologies may provide for outdoor play, on the back of our emerging insights, the project team developed a suite of preliminary BBC micro:bit based "Play Bits". The Play Bits were simple programs that we developed as a tool for probing further the potential for IoT technologies to augment and extend existing forms of play. The Play Bits either mimicked attributes of games the children in W1 and W2 had articulated to or played with us or provided specific functional qualities that we speculated could be appropriated into or reconfigured by children in their play. We developed an initial collection of 13 Play Bits supplied as an instructable co-created with Play Champions and written using Microsoft's MakeCode [33]. These Play Bits were: 1 . Name badge; 2 . Secret badge; 3 . Step counter; 4 . Rock-paper-scissors; 5. Compass 6. Magic Eight Ball; 7. Countdown; 8. Egg and spoon race; 9. Wink murder; 10.
Pancake flipper; 11. Fortnite dance picker; 12 . Magnet Detector; 13. Holding hands.

The Play Bits were used as part of a third workshop (W3). In this workshop, we worked with a different children's advocacy organization, who was interested in promoting both outdoor play and digital literacies for children. This workshop was again conducted over a single day. Due to the interests of our research partners, the day commenced by introducing the children to the BBC micro:bit platform, and demonstrating to them how they work and how they are programmed. This was a remarkably smooth initial activity, aided by the fact that many of the children participating in the workshop had seen or used the BBC micro:bit before. After this, we introduced the 13 Play Bits we had already developed, however, rather than just give the children the micro:bits with these different games and functions loaded onto them, we asked the children to select those Play Bits they were interested in and program them together in small groups. As such, each of our Play Bits was accompanied by an instructable that detailed how to build them. We also developed basic waterproof housings to allow the children to take the micro:bits outdoors in the slightly inclement weather on the day of the workshop.

Much of the remaining time of the workshop was spent with the children developing their Play Bits together and then being accompanied outdoors to try them out. As the day developed, we left space for children to alter the Play Bits to add new functions and adapt the programs (e.g. changing what sensed actions might trigger the display). The day ended with all the children coming together as a large group, with each small group demonstrating the Play Bits they had created during the day.

\subsection{Workshop 4: Inventing games with the play bits}

Following W3, we returned to TCT to run one final workshop, based on iterations of the Play Bits. While the third workshop had been very successful, we realized we had been relatively prescriptive with the children in terms of initiating their engagement with the Play Bits through predetermined examples. At the same time, some of the more interesting insights from the third workshop happened when children created entirely new games based on relatively simple and abstract functions of the micro:bits. Therefore, in this fourth workshop, we refined our Play Bits further to speak to their "play functions". These were not explicitly linked to specific games - rather the functions could be used as building 
blocks for play. The play functions were categorized as actions, navigation, counters and randomizers and illustrated through 1) a visual countdown that was started by shaking the device, 2) a function that display an $\mathrm{X}$ if you moved to quickly, 3) a shake counter that allowed children to see how many times the device had shaken, 4) a fall counter that detected the freefall of the device, 5) a compass display NSEW, 6) a magnet detector, and 7) a function to signal between two devices. Randomization was demonstrated by an additional function which responded to the device being shaken where it was available.

We then used these four function themes in the final workshop (W4), where we invited the children at TCT to use these as a starting point for inventing new games or incorporating them into their play. The workshop began with the researcher demonstrating each function. The children were then organized into two groups and allowed to play with the Play Bit functions as they saw fit. After a short period, we provided them with a menu outlining these functions and set them the challenge of inventing a game. We wanted participants to have the freedom to play in a self-directed way, while also being encouraged to adopt our BBC micro:bit functions within that play.

\subsection{Participants and Data Analysis}

For workshops at TCT participants were recruited through the center. For W3, the NGO advertised directly to people they worked with, on their website and through EventBrite but acting as the gatekeeper to ensure it met with their best practices of working with children. The make-up of each workshop follows: W1/W2 included 7 children ages 7-12, 4 girls and 4 boys (one boy withdrew), W3: 15 children ages 8-15, 9 girls and 6 boys. W4: 5 boys aged 7-10. In the following, names are annoymised.

The resulting data from our design ethnography included fieldnotes, notes from project meetings, and photos, videos, hand-drawn sketches, transcripts of audio recordings from workshops. This data set was qualitatively and collectively analyzed in a series of roundtable data sessions, from which materials were coded, organized into initial themes supported by empirical instances, and then refined to address the key questions of our study. Throughout, our sensitizing concepts helped us make sense of both the inspiration and ethnographic insight generated in the RtD context, for meaningfully relating interaction metaphors to participant expressions on forms and functions of artifacts and the environment, and for guiding us in selecting empirical instances to focus on in our analysis.

\section{FINDINGS}

Our analysis led to the generation of three themes that draw out the role of placemaking, the cultural influences that shaped play, how we saw rules changed, negotiated and adapted, and how the IoT device fitted this exploration.

\subsection{Place-making through Play}

Our design ethnography was driven by an interest in understanding how play and pervasive play with IoT resources may be engaged outdoors. Our workshops at TCT promoted rich discussion with the children on how they already played out in their local neighbourhood. Whilst W1 and W2 partly responded to concerns that children have limited opportunities to engage in outdoor play, the children highlighted a myriad of ways that they moved through and around the local environment through play. The drawings from the first activity in W1 were laden with examples of how they played outdoors, which were explored in more depth in the mapping activity and the neighbourhood walk. While walking around the neighborhood, the children took us to their homes and talked about their gardens as places they enjoyed ball games and played on the trampoline together. Relatedly, children also placed their activity cards in the gardens of friends, highlighting play between households. This urban area had relatively few green spaces; however, we visited two small wooded areas, and sat between roads and pavements in the town center- all of these were small microcosms of play.

It became clear that outdoor play was a form of placemaking and enabled the children to take some ownership over their local environment. This was observed most obviously in how they incorporated aspects of their immediate outdoor environment into their play. One example of this was during our drawing activities (Figure 1), where children depicted outdoor 'furniture' that had significance in how they played in the streets. Poppy referred at length to the green shape in the middle of her drawing (see Figure 1a). Under this she also drew a car and rubbish bin. She went on to explain:

"So, if you are hiding and the person tags then you have to chase them. But sometimes I make up a different part of it, so you have to run, normally I play it in my street and there 
are two speed bumps and you have to run past the first speed bump and back to the green box. There is a green box down my street and you have to hit it and say hide and seek chain tag so they can't get you." [Poppy]

The "green boxes" - metal cabinets holding the local telephone exchange for telecommunications access on the streets - frequently appeared in stories that the children shared of playing in their streets. They explained the boxes would be appropriated for a range of playful activities - such as Hide and Seek, hiding closely together in a game they call 'Sardines', Chain Tag, for climbing on, and for playing dancing games influenced by the computer game Fortnite, or just as a meeting point before going and play elsewhere. In street games, like the one described above, the urban environment offered markers, signs and street furniture that featured in rule-based games and more open play.

Placemaking also came through in how areas of the housing estate clearly had certain meanings for the children. Khloe told us she no longer lived on the estate, but still came to the Play Lab. As we walked around the estate, she said: "I always used to come on this tree and me and my friends used to climb it and it is a lot of memories here were we used to do things...". Similarly, several of the children frequently referred to a specific tree on the estate where they would meet and come together to play. Khloe drew a picture of herself climbing this tree on her play card, and when we walked through the estate proceeded to climb the tree and hung the card off it as the rest of the group looked on. Even this small section of green land, beside a busy road, was enough to prompt memories of spending time together, and of climbing trees and playing on rope swings.

\subsection{Negotiation of play and rules}

Throughout the course of our fieldwork, we observed a wide range of different forms and types of play from open, to rule-based and through to examples that blurred these. It was notable how the children - and indeed the play workers that ran many of the sessions we observed and participated in - would continuously engage in the iteration, development and negotiation of rules; sometimes to support social cohesion among their group, sometimes to ensure their play was inclusive, and sometimes to offset the disruptive behavior of individual children.

While we saw this occurring multiple times across our data, there was one specific instance where several negotiations co-existed and this illustrates the complexity of play and rules in practice. During W3 we played in the yard with a ball and encouraged the children to show us some games they might play. Initially we started throwing the ball around in what the children called, "Passy". Everyone enjoyed themselves to begin with, but after a while one child - Tom - became frustrated as he was not getting a shot, mainly because other children were "hogging the ball" or taking more turns than others. Because of his frustration, the group decided to introduce a new rule, that a player could not catch the ball consecutive times, making it more likely for everyone to get some time with the ball. The conviction of this rule became evident when one of our researchers threw the ball a second time, only to be given in trouble by the group, who were not shy in doing so. Before long, the play worker (Ian) on hand this day felt the group were "getting distracted" and decided to introduce some structure. He drew zones on the ground with chalk, each representing ten points and created a table on a nearby shipping crate to count points. Again, the game began without conflict until the youngest boy - Sam - threw the ball backwards and became upset as some of the other children laughed. Seeing this, the group decided Sam should get a "handicap", because he was smaller, and would be allowed to stand further forward and therefore have a greater chance of scoring. Ian drew another line on the ground in front of where he should stand. The boy settled down, threw the ball and scored, and was offered praise from the group through applause and enthusiastic shouting.

It was common to see play change through a social negotiation of the rules. We had observed how this was critical in keeping groups of children playing together. "Hogging the ball" required a rule-change that enabled everyone to have a shot. "Getting distracted" required a new kind of gameplay. Not "being as good" at the game as the other players led to the iteration of the rules to balance the playing field. The children were supportive in this effort and offered praise to keep the game going.

Negotiation of the rules did not always go smoothly, however. We observed several instances where the introduction of constraints to those children dominating game play, led them exclaiming "it wasn't fair" and that it was cheating. In other situations, we saw how play could completely breakdown as the group or an individual child refused to engage in rule negotiation. 
One particular ball game called 'It's a Bomb' was popular amongst the children. The game involved standing in a circle and passing an unexploded bomb. It began with the children chanting "It's a bomb, it's a bomb, it's a very big bomb", this was then followed by a countdown from ten while passing the ball around between players. At 'Zero' the children would shout "Boom!" and the last person to catch the ball was out of the game. Despite enjoying the game, we witnessed strategies that disrupted the group including refusing to catch the ball, hitting the ball away or holding it for too long.

In one such example children played 'It's a Bomb' where we witnessed a breakdown of the group dynamic with children refusing to play anymore. Poppy was starting to win consistently by holding the ball and throwing it at the very last minute, thus putting her chosen player out without any chance of passing it on. After several rounds of this, she throws the ball to Sam, at which point the group shouts "bang" and Sam is out. Sam was visibly upset, even more so than he had been earlier that day, and announced that Poppy was a "cheat" and walked away crying to sit beside the climbing frame. The group debates Poppies cheating, she becomes upset at being called a cheat and also storms out of the game.

As our examples here show, group coherence is a delicate balancing act that is easily disrupted. Additionally, some children are more resilient than others, either they have a stronger voice and are more controlling in the group or are better able to deal with emotional conflict. As expected, the evolution and existence of rules is deeply entwined with existing social structures; for instance, in workshops we found some children more vocal than others, and these same confident characters tended to be heavily involved in directing the game, for better or worse.

\subsection{Degrees of participation and spectating}

While playing games with the children, both digitally mediated and otherwise, we found outdoor play provided opportunities for creative social and physical play. For example, one child recalled playing on her trampoline in the garden, crediting the invention of two games to herself: "Crack the egg" and "Flip the pancake". She explained that both involve two people jumping on the trampoline. The first game involves jumping on another player. The second involves jumping beside another player and trying to flip them over. When asked what was best about the games, she exclaimed that they "get everyone excited and people cheer them on". There is a certain amount of amusement and silliness in jumping on another player and attempting to flip them over. As such, spectators were important participants in the game - while they got enjoyment from just viewing the action, they also actively shaped it through their laughter and enthusiastic engagement. In a similar vein, our Fortnite Dance Play Bit gave the children an excuse to show off their best Floss dance in front of the other children.

In another example, we used a PlayStation Move controller to facilitate play and this led us to consider further degrees of participation. One afternoon following the abandonment of the 'It's a Bomb' game (described above) we decided to create a quick digital intervention. Given that Sam had become upset with the rules and wanted to sit out, we introduced some structure and created a new role for Sam as an overseer (or "Fair Witness" [13]). This interventional role would give him additional control in the game by enabling him to participate and enforce the rules. We used a PS Move controller and a laptop connected to a Bluetooth speaker. A button on the controller started a fixed audio count down and another told the group to "throw!". To involve the children, we had them record audio on dictaphones before placing these in the game. This game brought some hilarity when they first heard the countdown and jointly shouted bomb sound. The game continued with Sam happier, he had been brought back into the game, albeit in a different role. As with much of the play we observed, after a playing a few more turns, the children moved on to something else.

\subsection{Leadership and facilitation}

It was also clear throughout our fieldwork that outdoor play was entwined the role of leading and facilitating. At one level this related to the ways in which specific children would take a lead in initiating play - such as Poppy who would take a proactive role in knocking on the doors of her friends to encourage them to come out, to others who would clearly direct what is actually played and with whom.

Demonstrations of leadership were also observed in our workshops in relation to the creation of new games and sharing and distributing them with a wider group. In preparation for W3, we included a "Fortnite dance" game. In response, two children in our Hackathon Lucas and Max - invented and facilitated a game they called "outdoor dance party". Lucas and Max wanted to 
demo their game, so we took the entire group outside when they returned after lunch. Taking a step back, we permitted the children to introduce and demo their game, something they did with great confidence. The two boys got everyone into four groups and gave them each a number between one and four. Lucas went on to explain their game: "So we have a dance party, whenever I shake this a song will play. But it will come up on here the number and whoever's number gets called has to dance". Max then began the game by announcing, "Let the humiliation begin... I mean fun... 3...2 ...1... go". Following the countdown Lucas shook his BBC micro:bit. The digit "3" appeared and a random song played. The other groups laughed as Group 3 awkwardly danced. Lucas shook the BBC micro:bit bit again and announced, "1". A member of a participating group shouted "Silliest dance... come on".

In this instance, Lucas and Max were given the opportunity to perform and act as facilitators of their game. They were particularly excited about being in charge and overseeing game play with both adults and children. We saw them express confidence and happiness performing in this role.

\subsection{Cultural Influences}

Children at TCT had a vivid imagination and would freely draw and chat about characters from movies, books and video games. During our initial play workshop Lucas drew himself with a Nerf Gun recreating Fortnite with his friends. W2 saw Sam draw a house out of Minecraft blocks and characters he had battled against in Lego Worlds. There was considerable chat about Harry Potter and a cross over with our chat about outdoor play and fantasy led Poppy to say she "Would love the invisibility cloak because I could play hide and seek with it". We found these cultural influences to have an impact on the kinds of outdoor games the children played or wanted to.

This was most significant during W4. To recap, participants were asked to create their own outdoor play using preprogramed micro:bits with simple functions and craft materials. Despite imagining participants would create rule-based games of a more traditional nature, like versions of tag and hide and seek, this group of boys were especially enthusiastic about creating outdoor versions of video games and movies. While being introduced to the micro:bits the children explored various games, namely: FIFA, Call of Duty, Fortnite and Star Wars.

\subsection{Adapting and extending play}

We have made a number of observations that suggest physical IoT devices could, in many cases, offer new expressions of outdoor play. Here we discuss some features of play with the BBC micro:bit that we have witnessed directly.

Firstly - the simplest of embodied interactions can encourage children to run around boisterously. During our Hackathon two children took a BBC micro:bit they had programmed with our pancake flipping code and ran around outside: hopping, skipping and jumping together. Every time they jumped, the pancake flipped. We have seen similar effects with both step and fall counters, with children challenging each other to get the highest number by running around and jumping.

Secondly - we found the children enjoyed making up their own games and experimenting with combinations of different BBC micro:bit functions alongside other materials they found lying around, like card and paper. For example, Melvin and Tom collaborated by programming different elements of a game and convened outside to play the game together. The game involved finding a magnet in the yard (most often a bush). One player would use the compass program to define coordinates (consisting of steps and bearings) and write this on a piece of paper. The second player then had to find the magnet using the BBC micro:bit compass and once close enough, the magnet detector design.

In another related instance, a group of children at W3 played Wink Murder and together experimented with different code and how that changed gameplay. They for example, decided: "it would be better with the buttons. The thing is with my hands is that they sometimes tremble." Further iterations led them to "change it to a skull to know you are dead." We found an important feature of the BBC micro:bit was being able to quickly and easily upload a program to friends devices. When trying out a new version of Wink Murder, one girl took the lead making this on her computer before sharing it with everyone in the group.

In another example, that also highlights the influence of computer games, a group of boys became increasingly interested in recreating Call of Duty. Lucas, Zander and the play facilitator (Rose) considered how they might enact weapons and recreate elements of the video game. Lucas said to Zander, "I want to make a shooting game". Picking up the BBC micro:bit and shaking it, Lucas said, 
"You could use the shake one as a gun", which prompted Zander to make gun noises and gesture as if holding the weapon. Considering more carefully the functions available, Rose explained, "You could use your countdown as one. This is a magnet one, so you could have a countdown and a magnet and if you want a shoot game the bullets could be 'em' magnetic". Lucas continues to expand on these ideas: "the bullets are magnetic and you could have countdowns and compass as a sniper" and Zander replies, "I could use the countdown to countdown your bullets". Getting increasingly excited, Zander announces, "Sniper!" and makes further gun noises, while Lucas moves on to generate ideas for a grenade. War games were not actively encouraged at TCT, however, children were often given the freedom to define their own play. Rose quizzed Zander about his fascination with war, asking, "Why has it always got to be about war? Can we not have peace in the country, not war." Zander asked, "What is wrong with war?", before Rose retorted, "There is too much war and it is not nice.".

Alongside children creatively appropriating micro:bits, we have seen the digital functionality itself become redundant. Lucas decided he wanted to make a Lightsaber, placing a magnet on the end and using the magnet detector to count the number of times an opponent was jabbed. It wasn't long before the group had settled on the idea of having a battle outdoors with paper Lightsabers. Throughout our time at TCT we found the children were good at rallying around ideas and working together when forming strategies for games they could play. Having seen Lucas make himself a Lightsaber using rolled up paper, the group collaborated so that everyone had one. Lucas took the lead on this one by directing and helping his mates, "[Lucas], will you help us make a Lightsaber out of paper." Lucas replies and demonstrates, "Just wrap it up into a thing and then sticky tape the seam where you folded it". "Can you help us?". The children enjoyed decorating their Lightsabers and discussed how they would color them in, Lucas gave them some ideas for their designs, "Why not yellow, yellow is a color in Star Wars. Yellow means power. Blue basically means everything that a Jedi stands for. Red is everything the Sith stand for".

Meanwhile, one of our researchers had been putting together some additional code that counted up when a magnet was detected, expecting the children to bring this back into their play. However, the children had quickly dawned lab coats from the PlayLab (as a suitable Jedi cloak) and ventured outside to re-enact scenes from Star Wars. They were so excited about their newly created Lightsabers and being characters from the movie, that the digital functionality was ignored. Here, they ran around the yard, sometimes in twos, sometimes in groups, making gestures, hitting their paper Lightsabers together and jabbing. The children played over twentyfive minutes and only ended when one participant became too rough, causing another to protest. The Play Champion asked what the children were doing which she relayed as "it is free play and they just lead it and do what they want themselves". Free play of this kind was encouraged, alongside more structured games and activities. Where previously we had witnessed rulebased games, it seemed the only rules sacred in this play was to remain in role as a character from Star Wars and to not deliberately hurt each other. In this instance, the BBC micro:bit functionality became redundant and in hindsight, the creativity inside being caught up in openended play was more influential than the literal counting of hits with the Lightsaber.

\section{DISCUSSION}

We have reported on a design ethnography where, through a series of co-creative activities with children, we explored their outdoor play and its benefits (W1), unpacked the different games they played (W2), how this pointed to opportunities with IoT (W3), and how IoT technologies facilitated more pervasive open-ended play (as in [55]) extending play from indoors to out (W4). Our findings highlight how the children both cherished playing outdoors, and actively sought opportunities to play out. The workshop activities illustrated the significance of outdoor play for feeling a sense of belonging in the local neighborhood, as well as the positive potential around the development of individual 'resilience' [16]. We saw how children drew on a widerange of games that stimulated and were incorporated into outdoor play; while some of these were rule-based, many formed creative combinations of different games, as rules were made up, iterated and negotiated in response to group dynamics and taking inspiration from what was discovered in the environment. Significantly, we gained insight on how IoT could augment and enhance existing play: how the capabilities of simple connected devices fitted with open-ended play; and supporting hybrid interaction, digitally augmenting social and physical play. 
We discuss our analytic reflections in relation to extant HCI and IDC studies that consider how pervasive technology can support open-ended play, and how IoT devices invite creativity as interactive tangibles [8]. We explore this through discussion points that laud IoT as a tool for research in this area and reflect on the social engagement that is underexplored in these communities.

\subsection{IoT to Support Creativity in Open-ended Play}

In exploring and creating play (with IoT), our design space was shaped by the children's sense of place, by cultural influences on them, and by their own detailed descriptions of gameplay and rules. Varied and original instances of play warranted markedly different configurations of technology in response. We find it valuable to recognize and provide devices that are configurable across a spectrum of complexity, where at one end, programs on devices can scaffold the 'performance frame' of entire games such as Wink Murder in W3, and, at the other end, devices in W4 were programmed by children to count a particular physical action (as in [19]). Our sensitizing concepts of Cocreation and Clear function / Open purpose guided our design of prototypes that were intelligible to children with minimal facilitation or prompt. Our approach has been to use the children's own play - often reducing the digital complexity as much as possible, whereupon it became the simplest version of the game or even an isolated game mechanic or off-the-shelf component. The simple functions of the Play Bits were readily understandable and appropriable by children, enabling them to lead, build on our designs and demonstrate their creations to us. Children were also able to choose to use the designs as resources without adapting them, and then creatively ascribe meaning [27].

Approaches adopted by other researchers have resulted in creating bespoke designs that are more complex, albeit able to embody the characteristics of traditional games (as in [53]). Our approach with Play Bits provides accessible starting points for play which enables children to change the gameplay to fit their changing moods which are often fluid and whimsical, an approach that arguably aligns with how children enjoy open-ended play $[7,55]$. Our Play Bits in W3 and W4 were based on play observed in our ethnography from physical actions which provided play functions like jumping and navigation, to ones that necessitated accompanying player rules, like counters and randomizers. While there were successes around more constrained games, those that were most successful were most open to interpretation in terms of use. It was the simplicity of the IOT device and simplicity of the play functions (again Clear function / Open purpose) which helped foster this child-led creativity. IoT devices like the accessible BBC micro:bit are well matched to such outdoor play because play can be readily "mapped" to the device. Physical actions like discrete embodied interactional gestures can be associated with sensors packaged on the device, while rule-based play can be complemented with IOT functions like counters and random number generators.

Importantly, our IoT designs encouraged creative appropriation to be taken outside. The form factor of the $\mathrm{BBC}$ micro:bit is small enough to be held (or hidden) in children's pocket (ideal for leaping over walls), c.f. armsout interactions [19]. The sensitizing concept of porosity additionally guided us in thinking about how IoT devices can afford outdoor play. In W3, the very act of 'labelling' a game to program as an 'outdoors game' inevitably led the participating children to download it quickly onto the BBC micro:bit and run outside to play with it. In W4, children moved outdoors to have more space to play with the IoT 'Lightsabers' they had programmed indoors. Our provided resources therefore encouraged making activities that could be nudged or invited outside play.

\subsection{Pervasive play for Place-making and Resilience}

Our first area of investigation was play already occurring in the local neighborhood. We found that the children living near TCT had a meaningful connection to the local outdoor spaces despite the voiced barriers and boundaries. Indeed, the children appeared resilient and imaginative when playing out. We evidenced groups who played together, elements of the environment becoming central to play e.g. the green box became a place to meet, to hide together packed in their game 'Sardines', hide alone, to place prisoners and also lead from. Children also identified other places of shared significance e.g. streets, trees, road intersection. These locations provide opportunity to take portable IOT devices to, or augment with waterproofed IOT waiting in situ, in or on street furniture, that might be subverted in acts of placemaking for their own play needs.

A key insight from our ethnography is how the IoT designs supported sociality, leadership, and social negotiation to facilitate and sustain group play in the wider context of community cohesion. The (reJconfigurability of multiple linked devices supported 
different roles e.g. making an interface for the role of "fair witness" described [13] and even creating a dance challenge. We see how this could be part of supporting developmental growth in the children and a particular kind of 'social resilience' [23] where expressions of sociality between the children sustain their play together and can help children play well together [13]. IOT can help support this through provision of powerful networking, programmed as a simple "radio" without being encumbered by pairing or other potentially problematic interfaces. This connectivity can easily support devolved and shared control of outdoor gameplay. For example, in our findings on negotiating play and rules, we find opportunities for IoT enabled play to re-assign roles in real-time between a group of children across shared or individual devices.

We have also reflected on resilience in another way: as resilience in place. We observed children in the TCT community talked about responding to calls from friends to play out through the windows of their homes. Our field observations led us to consider scenarios in which small IoT devices could be grabbed on the way out of home to play, and even be left outdoors making that barrier between inside and outside more porous. In the study we gave waterproof housing for IoT devices in case of poor weather that might otherwise hinder children's play. Leading from this, we may reconsider children's resilience in terms of not being deterred by the weather to play in specific outdoor spaces. What we highlight is the need for IoT resources to be physically robust, while still allowing children to set their own goals and rules, and therefore contrast with centers and playgrounds which offer more manufactured and fixed opportunities for play [23].

Our findings herein contextualize IoT resources and their design potential within a broad social context that is connected to the social dynamics of a community-inplace, and therefore contribute a more nuanced understanding of place and community to the growing corpus of HCI work on digital playing out e.g. $[3,4,40]$, from a UK perspective.

\subsection{IoT prototyping for Co-creative RtD}

The Play Bits provide starting points for children's play in terms of 'ready-made' functionality. But they also become accessible resources for playful and co-creative RtD; children were able to grasp the task of programming a game on their BBC micro:bit and then decide whether of not it would fit with their play. They were then seen to create or change their own game mechanics or fine-tuning existing rules. Our methodological approach therefore illuminated the nature of their creative appropriation, so we could observe it in the field and in the context of unfolding social interaction. Our RtD approach of offering highly configurable resources connects with craft-led approaches to IoT and what Buechley and Perner-Wilson coin a "kit-of-no-parts" [56] so children can define their own play. As with [19], we find Scratch-styled graphical programming languages for IoT devices introduced programming to children in a relatable context, empowering them to them be creative with others [28]. This encourages participation in research; we found in our work that both the idea and experience of outdoor play could entice young people to explore IoT who would not normally be interested in programming.

\section{CONCLUSION}

In this paper, we reported on a design ethnography that explored how children play out and the opportunities for IoT technologies to extend pervasive play to outdoors. Through co-creative activities and the use of digital resources, we highlighted how play was enmeshed with processes of placemaking, with the development of confidence and leadership skills, and how it promoted multiple modes of participation and potential for developing resilience. Our findings suggest ways forward for designing future IoT artefacts and systems that promote new forms of pervasive, open-ended and creative play outdoors. We encourage the further design exploration of IoT resources for supporting children in co-creatively defining their outdoor play in local places that have significance to them.

\section{ACKNOWLEDGMENTS}

We thank our research participants for their time and contributions and NE Youth for their support and guidance in the third workshop. This research is funded by EPSRC (EP/P025544/2).

\section{REFERENCES}

[1] Marie-Jeanne Aarts, Wanda Wendel-Vos, Hans A.M. van Oers, Ien A.M. van de Goor, and Albertine J. Schuit. 2010. Environmental Determinants of Outdoor Play in Children. American Journal of Preventive Medicine 39, 3: 212-219. DOI: https://doi.org/10.1016/j.amepre.2010.05.008

[2] June Ahn, Elizabeth Bonsignore, Derek L. Hansen, Kari Kraus, and Carman Neustaedter. 2016. Pervasive Play. In Proceedings of the 2016 CHI Conference Extended Abstracts on Human Factors in Computing Systems (CHI EA '16). ACM, 
New York, NY, USA, 3317-3324. DOI: https://doi.org/10.1145/2851581.2856473

[3] Jon Back, Caspar Heeffer, Susan Paget, Andreas Rau, Eva Lotta Sallnäs Pysander, and Annika Waern. 2016. Designing for Children's Outdoor Play. In Proceedings of the 2016 ACM Conference on Designing Interactive Systems (DIS '16). ACM, New York, NY, USA, 28-38. DOI: https://doi.org/10.1145/2901790.2901875

[4] Jon Back, Laia Turmo Vidal, Annika Waern, Susan Paget, and Eva-Lotta Sallnäs Pysander. 2018. Playing Close to Home: Interaction and Emerging Play in Outdoor Play Installations. In Proceedings of the $2018 \mathrm{CHI}$ Conference on Human Factors in Computing Systems (CHI '18). ACM, New York, NY, USA, Paper 156, 11 pages. DOI: https://doi.org/10.1145/3173574.3173730

[5] BBC Media Centre, microbit-first-year (2017), Retrieved September 2018 , https://www.bbc.co.uk/mediacentre/latestnews/2017/mi crobit-first-year

[6] BBC (2012), Safety fears 'hinder outdoor play', says survey.

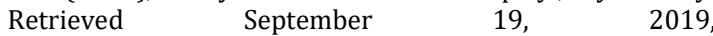
https://www.bbc.co.uk/news/education-19065224

[7] Tilde Bekker, Janienke Sturm, and Berry Eggen. 2010. Designing playful interactions for social interaction and physical play. Personal Ubiquitous Comput. 14, 5 (July 2010), 385-396. DOI: http://dx.doi.org/10.1007/s00779009-0264-1

[8] Tilde Bekker and Janienke Sturm. 2009. Stimulating physical and social activity through open-ended play. In Proceedings of the 8th International Conference on Interaction Design and Children (IDC '09). ACM, New York, NY, USA, 309-312. DOI: http://dx.doi.org/10.1145/1551788.1551869

[9] Hillary L. Burdette and Robert C. Whitaker (2005). A National Study of Neighborhood Safety, Outdoor Play, Television Viewing, and Obesity in Preschool Children. Pediatrics, 116(3), 657-662. DOI: https://doi.org/10.1542/peds.2004-2443

[10] Damian Carrington, Guardian (2016), Retrieved Sept 19, 20019 from https://www.theguardian.com/environment/2016/mar/2 5/three-quarters-of-uk-children-spend-less-time-outdoorsthan-prison-inmates-survey

[11] Deborah A. Cohen, Gerald Hunter, Stephanie Williamson, and Tamara Dubowitz. 2016. Are Food Deserts Also Play Deserts? Journal of Urban Health 93, 2: 235-243. https://doi.org/10.1007/s11524-015-0024-7

[12] Clara Crivellaro, Alex Taylor, Vasillis Vlachokyriakos, Rob Comber, Bettina Nissen, and Peter Wright. 2016. Re-Making Places: HCI, 'Community Building' and Change. In Proceedings of the $2016 \mathrm{CHI}$ Conference on Human Factors in Computing Systems (CHI '16). ACM, New York, NY, USA, 2958-2969. DOI: https://doi.org/10.1145/2858036.2858332

[13] Bernard DeKoven. 2013. The Well-Played Game: A Player's Philosophy. The MIT Press.

[14] Guy Faulkner, Raktim Mitra, Ron Buliung, Caroline Fusco \& Michelle Stone (2015) Children's outdoor playtime, physical activity, and parental perceptions of the neighbourhood environment, International Journal of Play, 4:1, 84-97, DOI: 10.1080/21594937.2015.1017303

[15] Natalia Georgiadi, Eleni Kokkoli-Papadopoulou, George Kordatos, Konstantinos Partheniadis, Manos Sparakis, Panayiotis Koutsabasis, Spyros Vosinakis, Dimitris Zissis, and Modestos Stavrakis. 2016. A pervasive role-playing game for introducing elementary school students to archaeology. In Proceedings of the 18th International Conference on Human-Computer Interaction with Mobile
Devices and Services Adjunct (MobileHCI '16). ACM, New York, NY, USA, 1016-1020. DOI: https://doi.org/10.1145/2957265.2963117

[16] Kenneth R. Ginsburg. 2007. The Importance of Play in Promoting Healthy Child Development and Maintaining Strong Parent-Child Bonds. PEDIATRICS 119, 1, 182-191. https://doi.org/10.1542/peds.2006-2697

[17] Gurwitsch, A. Human Encounters in the Social World. Duquesne University Press, Pittsburgh, 1979.

[18] Jon Henley, Why our children need to get outside and engage with nature, Guardian (2010), Retrieved 19, 20s18 from https://www.theguardian.com/lifeandstyle/2010/aug/16/ childre-nature-outside-play-health

[19] Tom Hitron, Itamar Apelblat, Iddo Wald, Eitan Moriano, Andrey Grishko, Idan David, Avihay Bar, and Oren Zuckerman. 2017. Scratch Nodes: Coding Outdoor Play Experiences to enhance Social-Physical Interaction. In Proceedings of the 2017 Conference on Interaction Design and Children (IDC '17). ACM, New York, NY, USA, 601-607. DOI: https://doi.org/10.1145/3078072.3084331

[20] Tom Hitron, Idan David, Netta Ofer, Andrey Grishko, Iddo Yehoshua Wald, Hadas Erel, and Oren Zuckerman. 2018. Digital Outdoor Play: Benefits and Risks from an Interaction Design Perspective. In Proceedings of the 2018 CHI Conference on Human Factors in Computing Systems (CHI '18). ACM, New York, NY, USA, Paper 284, 13 pages. DOI: https://doi.org/10.1145/3173574.3173858

[21] John Maguire, BBC (2012), Residential road closures 'to allow children to play'. Retrieved September 19, 2018 from https://www.bbc.co.uk/news/av/uk-

18687191/residential-road-closures-to-allow-children-toplay

[22] Michael D. Jones, Zann Anderson, Jonna Häkkilä, Keith Cheverst, and Florian Daiber. 2018. HCI Outdoors: Understanding Human-Computer Interaction in Outdoor Recreation. In Extended Abstracts of the 2018 CHI Conference on Human Factors in Computing Systems (CHI EA '18). ACM, New York, NY, USA, Paper W12, 8 pages. DOI: https://doi.org/10.1145/3170427.3170624

[23] Stuart Lester and Wendy Russell. 2008. Play for a Change. Play for a change Summary report-Play, Policy and Practice: A review of contemporary perspectives. Retrieved September 19, 2019 from http://www.playengland.org.uk/media/120519/play-fora-change-summary.pdf

[24] Duri Long, Hannah Guthrie, and Brian Magerko. 2018. Don't steal my balloons: designing for musical adult-child ludic engagement. In Proceedings of the 17th ACM Conference on Interaction Design and Children (IDC '18). ACM, New York, NY, USA, 657-662. DOI: https://doi.org/10.1145/3202185.3210795

[25] Lennart E. Nacke, Anna Cox, Regan L. Mandryk, and Paul Cairns. 2016. SIGCHI Games: The Scope of Games and Play Research at CHI. In Proceedings of the 2016 CHI Conference Extended Abstracts on Human Factors in Computing Systems (CHI EA '16). ACM, New York, NY, USA, 1088-1091. DOI: https://doi.org/10.1145/2851581.2886438

[26] Laura Lentini and Françoise Decortis. 2010. Space and places: when interacting with and in physical space becomes a meaningful experience. Personal and Ubiquitous Computing 14, 5: 407-415. DOI: https://doi.org/10.1007/s00779-009-0267-y

[27] Angeline S. Lillard, Matthew D. Lerner, Emily J. Hopkins, Rebecca A. Dore, Eric D. Smith, and Carolyn M. Palmquist. 2013. The impact of pretend play on children's development: A review of the evidence. Psychological 
Bulletin 139, $1: \quad 1-34 . \quad$ DOI: https://doi.org/10.1037/a0029321.

[28] Lifelong Kindergarten Group, MIT Media Lab. 2007 Scratch. Retrieved $20 \quad$ September 2019 from https://scratch.mit.edu/.

[29] John Maguire, BBC (2012), Residential road closures 'to allow children to play'. Retrieved September 19, 2018 from https://www.bbc.co.uk/news/av/uk-

18687191/residential-road-closures-to-allow-children-toplay

[30] Marianna Obrist, Pablo Cesar, David Geerts, Tom Bartindale, and Elizabeth F. Churchill. 2015. Online video and interactive TV experiences. interactions 22, 5 (August 2015), 32-37. DOI: https://doi.org/10.1145/2799629

[31] Kevin Marshall, Gavin Wood, Janet C. Read, Svetlana (Lana) Yarosh, Madeline Balaam, and Jung-Joo Lee. 2015. Supporting Children to Engage in Play for Wellbeing. In Proceedings of the 33rd Annual ACM Conference Extended Abstracts on Human Factors in Computing Systems (CHI EA '15). ACM, New York, NY, USA, 2445-2448. DOI: https://doi.org/10.1145/2702613.2702658

[32] George Herbert Mead. Mind, self and society. Vol. 111. University of Chicago Press.: Chicago, 1934

[33] Microsoft MakeCode, BBC micro:bit Educational Foundation, https://microbit.org (2017), Retrieved September 2018, https://makecode.microbit.org/\#

[34] Stephen Moss. (2012). Natural Childhood. Swindon, UK. Retrieved https://www.nationaltrust.org.uk/documents/read-ournatural-childhood-report.pdf

[35] Ofcom, (2017) Children and Parents: Media Use and Attitudes Report, Retrieved September 19, 2019 from https://www.ofcom.org.uk/_data/assets/pdf_file/0020/1 08182/children-parents-media-use-attitudes-2017.pdf

[36] Nazia Parveen. 2015, Daily Mail (2015). Retrieved 20 September 2019 from https://www.dailymail.co.uk/news/article-3019573/Thesimple-outdoor-pleasures-missed-today-s-computerloving-children.html

[37] Sean Peacock, Robert Anderson, and Clara Crivellaro. 2018 Streets for People: Engaging Children in Placemaking Through a Socio-technical Process. In Proceedings of the 2018 CHI Conference on Human Factors in Computing Systems (CHI '18). ACM, New York, NY, USA, Paper 327, 14 pages. DOI: https://doi.org/10.1145/3173574.3173901

[38] A.D. Pellegrini and Lee Galda (1993). Ten Years After: A Reexamination of Symbolic Play and Literacy Research. Reading Research Quarterly, 28(2), 162-175. https://doi.org/10.2307/747887.

[39] Public Health England (2014), Everybody active, every day: framework for physical activity, 2014, Retrieved September 2018

from https://www.gov.uk/government/publications/everybody -active-every-day-a-framework-to-embed-physicalactivity-into-daily-life

[40] Janet C. Read, Panos Markopoulos, Narcis Parés, Juan Pablo Hourcade, and Alissa N. Antle. 2008. Child computer interaction. In CHI '08 Extended Abstracts on Human Factors in Computing Systems (CHI EA '08). ACM, New York, NY, USA, 2419-2422. DOI: https://doi.org/10.1145/1358628.1358697

[41] Marta Ferraz, Paul E. Resta, and Afonso O'neill. 2017. Wholebody interaction in natural environments benefits children's cognitive function compared to sedentary interaction indoors. In Proceedings of the 8th Augmented Human International Conference (AH '17). ACM, New York, NY, USA
Article $\quad 8, \quad 11 \quad$ pages. DOI: https://doi.org/10.1145/3041164.3041177

[42] Rideout, V. J., Ulla, M. A., Foehr, G., \& Roberts, D. F. (2010). GENERATION M2 Media in the Lives of 8-to 18-Year-Olds. Menlo Park, CA. Retrieved from https://files.eric.ed.gov/fulltext/ED527859.pdf

[43] Yvonne Rogers. 2015. Playful Interactions in Public. In Proceedings of the 2015 Annual Symposium on ComputerHuman Interaction in Play (CHI PLAY '15). ACM, New York, NY, USA, 127-127. DOI https://doi.org/10.1145/2793107.2801717

[44] Tony Salvador, Genevieve Bell, and Ken Anderson. "Design ethnography." Design Management Journal (Former Series) 10, no. 4 (1999): 35-41.

[45] Ben Schouten, Panos Markopoulos, Toups, Z., Cairns, P., \& Bekker, T. (2017). Proceedings of the Annual Symposium on Computer-Human Interaction in Play. In CHI PLAY'17 Amsterdam. New York, NY: ACM - Association for Computing Machinery. Retrieved from http://chiplay.org

[46] Elena Márquez Segura (2016). Embodied Core Mechanics Designing for movement-based co-located play. Uppsala University.

[47] Elena Márquez Segura, Laia Turmo Vidal, Asreen Rostami, and Annika Waern. 2016. Embodied Sketching. In Proceedings of the $2016 \mathrm{CHI}$ Conference on Human Factors in Computing Systems (CHI '16). ACM, New York, NY, USA 6014-6027. https://doi.org/10.1145/2858036.2858486

[48] Susanne Seitinger. 2006. An ecological approach to children's playground props. In Proceedings of the 2006 conference on Interaction design and children (IDC '06). ACM, New York, NY, USA, 117-120. DOI: https://doi.org/10.1145/1139073.1139103

[49] Ben Shaw, Martha Bicket, Bridget Elliott, Ben Fagan-Watson, Elisabetta Mocca and Mayer Hillman, 2015. Children's Independent Mobility: an international comparison and recommendations for action. Retrievd September 2018 from http://www.psi.org.uk/children_mobility.

[50] Anita Singh, 2014. Telegraph. Retrieved September 2018, https://www.telegraph.co.uk/lifestyle/10960864/Mostchildren-play-outside-for-less-than-an-hour-a-day.html

[51] George Smith, Kathy Sylva, Pam Sammons, Teresa Smith, and Aghogho Omonigho. Stop Start. Survival, decline or closure? Children's centres in England, 2018. Retrieved September 2018, content/uploads/2018/04/StopStart-FINAL.pdf

[52] Iris Soute, Maurits Kaptein, and Panos Markopoulos. 2009. Evaluating outdoor play for children: virtual vs. tangible game objects in pervasive games. In Proceedings of the 8th International Conference on Interaction Design and Children (IDC '09). ACM, New York, NY, USA, 250-253. DOI: http://dx.doi.org/10.1145/1551788.1551844

[53] Iris Soute, Panos Markopoulos, \& Magielse, R. (2010). Head Up Games: Combining the best of both worlds by merging traditional and digital play. Personal and Ubiquitous Computing, 14(5), 435-444. https://doi.org/10.1007/s00779-009-0265-0

[54] Stappers, Pieter, and Elisa Giaccardi. "The Encyclopedia of Human-Computer Interaction, 43. Research through Design."

[55] Linda de Valk, Tilde Bekker, and Berry Eggen. 2013. Leaving room for improvisation: towards a design approach for open-ended play. In Proceedings of the 12th International Conference on Interaction Design and Children (IDC '13). ACM, New York, NY, USA, 92-101. DOI: http://dx.doi.org/10.1145/2485760.2485771 
[56] Hannah Perner-Wilson, Leah Buechley, and Mika Satomi. 2011. Handcrafting textile interfaces from a kit-of-no-parts. In Proceedings of the fifth international conference on
Tangible, embedded, and embodied interaction - TEI '11. DOI: https://doi.org/10.1145/1935701.1935715 